\title{
Prospective Study of GMO in Korea: Harnessing GMO for Solving Problems of Climate Change
}

\author{
Sungmin Lee and Ha Eun Chun
}

\begin{abstract}
There is no doubt that the climate change is a pressing worldwide issue, considering its impacts on both the environment and the society, and various scientific means are to be adopted to solve this problem. We conducted a prospective study of GMO in Republic of Korea and recognized its potential to solve the problem of climate change. Its ability to endure harsh conditions and improve productivity can extend the range of possibilities in restricting climate change. This thesis shows the status quo in GMO research, discusses toward which direction it should gear to promote further development, and addresses the pros and cons of GMO, along with our own outlooks on prospects of future GMO research.
\end{abstract}

Index Terms-Biosafety, climate change, genetically modified organisms (GMO), genetic engineering.

\section{INTRODUCTION}

Throughout the history, Earth has undergone countless geological and climatic transformations that have come to shape the planet of today. Among them is the climatic change; average temperature of the globe has inclined and declined both gradually and suddenly especially during the ice ages. Yet recent discoveries indicate that the situation is more severe than that of any other epochs-average temperature of Earth has increased rapidly, affecting our ecology negatively.

Many scientific means have been suggested and tested to resolve this problem, yet they turned out to be insufficient. Harnessing GMO is fairly a recent idea to be applied to climate change and therefore ensues contentious issues, mostly regarding safety, although its efficacy has already been exhibited in agricultural industry.

Thus, it is important that science and technology industries thoroughly understand merits and demerits, discuss alternatives, and scrutinize over its possibility as one of the most prospective technologies.

\section{ANXIETY OVER GMO AND THE TRUTH}

From the very first development of GMO to this day, practicality of GMO has always been the target of endless controversy. Beyond reasonable concerns over probable shortcomings that exist in every introductory phase of accepting a new technology, unscientific rumors have emerged and spread to the point that they hamper proper speculation on GMO. Consequently, it is necessary that the

Manuscript received August 30, 2013; revised December 2, 2013.

Sungmin Lee and Ha Eun Chun are with Hankuk Academy of Foreign Studies (e-mail: leesm08@gmail.com, haeunchun@gmail.com). public understands the gravity of issues concerning GMO and discriminates facts from figments.

\section{A. Harms of Inappropriate Genetic Modification}

GM products accessible to consumers guarantee their safety, having passed strict examination on possible toxicity and drawbacks (by December of 2011, GMOs including beans, corns, cotton plants, potatoes etc. had passed the domestic examination on biosafety in Korea [1]). However, public awareness of GMO is yet to be enough; people have little understanding of the procedure and do not recognize positive aspects but rather allege disadvantages of these products. In 2011, when Korea Biosafety Clearing House conducted a survey on public recognition of domestic GMO, only $56.4 \%$ agreed that GM technology has benefits, while at least $90 \%$ of participants answered that there is an urgent need to establish further measures in the treatment, storing, and distribution of GMO. Their claim was that genetic engineering may bring inappropriate genetic modification within ecology-technology can never be considered perfect as long as it is developed by humans.

One of the most well-known experiments that corroborates the arguments of those who oppose GMO is called Pusztai affair, conducted by Dr. Arpad Pusztai, a Hungarian biochemist who worked at the Rowett Research Institue in Abereen, Scotland. Dr. Pusztai started a research on GM potatoes by observing two groups of rats, one fed with Desiree Red potatoes and the other with GM potatoes. It turned out that the rats which fed on GM products suffered from damages in their immune systems and intestines. He eventually broadcasted the results on a television program, which instigated the public, thus contributing to the long-held mistrust of GMO's safety. Yet, soon, his experiments turned out to be flawed; the GM potatoes he used had not passed the biosafety examination yet and contained high possibility of being pathogenic. Although Pusztai's study was proven incorrect, it nevertheless remains as a major falsehood in GMO research.

More than $50 \%$ of imported corns and more than $70 \%$ of imported beans are genetically modified. And not all of them, including soybeans and sugars, are labeled as GM products. However, this is not due to inattentiveness of the government but to scientific procedure. Because oils made from beans and corns consist of lipid, genes for GMO are removed in manufacturing process [2]. The factors for possible genetic problems lie within the genes, and the rest of components such as protein and cellulose do not make negative contributions. Currently, the United States has made the identifying process optional on foods processed twice, and the European Union has made it mandatory to 
identify and label every GM product for the sake of the public.

The Brazil nut case also demonstrates the lack of public understanding on genetic engineering. Pioneer Hi-Bred company, now known as DuPont Pioneer, has developed GM beans by injecting $2 \mathrm{~S}$ albumin gene from Brazil nut in order to improve the amount of essential amino acids included in soybeans. Unfortunately, during the trials, the researchers detected allergenic responses from GM soybeans and immediately discontinued the study. Ever since, this case has been frequently cited to show potential danger of GMO. Yet the problem was due not to the faulty GM technology but to the gene $2 \mathrm{~S}$ albumin itself.

Along with such misinterpreted experiments, mistrust on governmental examination impedes further growth of GMO. No technology can guarantee perfect safety and eliminate the possibility of noticing unforeseen negative effects. Yet, it takes from five to ten years on average to develop one GM product, and another ten to twenty years to introduce it to a market. Considering the fact that most of the genetic problems have been found during investigations and trials until now, and that there has not been any specific accident, GMO development definitely has its merits, as long as researchers conduct studies with the awareness of its shortcomings. Nations worldwide have cooperated on bioindustry through various means such as the Cartagena Protocol on Biosafety-drawbacks of genetic engineering are not to hamper further development, but to improve it.

\section{B. Damage on Ecology and Biological Diversity}

One of the effects that GMO has on the environment is damage on ecological diversity. There are two major problems of GMO mingling with non-modified species: unification of farm breeds species and ecological chaos caused by gene transfer.

The claim regarding environmental diversity comes from misunderstanding the essence of agriculture. Throughout the history, agricultural development of human race has been directed towards domesticating nature. Men have selected the most appropriate breed of all and reared it, whether it is a crop or a livestock. This process has resulted in decrease of environmental diversity, and it was inevitable; obtaining resources and benefiting from nature were the most important. Accusing GMO of limiting biodiversity is thus unreasonable-were it not for restricting biodiversity, agricultural development wouldn't have been possible. Besides, various companies' GMO products contain different strains of gene composition. Therefore, concerns about biological diversity are not related directly to harms of GMO.

There have been numerous efforts to prevent GM crops from mingling with natural crops. Installing fences was considered to be one good option though it is hard to block. It is true that intractable mixture of crops lead to genetic recombination, as in the case in which a new DNA recombines with a different organism. It is also true that it is impossible to prevent these problems categorically and deny potential ecological harms GMO might bring about. Yet for these reasons, we shouldn't stop but maintain rigorous measures toward GMO research so that it can be accepted to be used.

\section{OUTLOOK ON GMO AS AN ALTERNATIVE FOR PROBlems OF Climate CHANGE}

\section{A. Realistic Solutions for Food Shortage}

Many problems arise due to climate change, and global food shortage is no exception to them. In fact, although the world population is expected to increase by three billion within 50 years, there are not enough water and land resources to cope with such overpopulation. Climate change is definitely aggravating already-worsened situation; agriculture is vulnerable to even the slightest change in average temperature of the Earth climate. Damage of crops production may reach $27 \%$ at the least and $32 \%$ at the greatest in all African regions by the end of 2050. As for the South Asian countries, rice production may decrease by about $14.3 \%$ to $14.5 \%$ in 2050 . These statistics show the necessity of GMO technology which may provide effective alternative for climate change.

GM technology improves crop harvest by developing organisms well-fit for the varying environment. For example, injecting genes that withstand harsh climates enable GM products to sustain themselves in even the worst situation [3]. Crops resistant to bug attacks and made to survive in arid soil are also very useful. With researchers conducting studies to make crops withstand severe situations, some crops have already been developed to endure blight and protect themselves from harmful insects. Injecting Bacillus thuringiensis (Bt), which contains insecticidal toxins, into corns to help them self-sterilize [4] is one example of currently-being developed methods.

Results of GMO development for climate change are as enumerated: corns that only require $75 \%$ of water needed for natural corns, rice plants and wheat invulnerable to aridity, rice plants that survive in high temperatures and attain enough water in a short period (Hanareum II, Dasan I / Dami, Hoban, Cheongmyung, Choeun-Byu) [5].

With unexpected climate change affecting the world more than ever before, efforts to distribute crops effectively are necessary. GMO has already successfully contributed to such a need. In fact, most of today's agricultural society depends heavily on GMO production, which, for long years of research, has proven to be safe. According to a thesis of the Institute of Mosim and Salim titled The Age of Crises of Climate Change, Agriculture, and Food Production, abrupt food problems due to the climate change' are now established facts [6]. Golden Waves Opening the Future by Kyungmin Chun states that $77 \%$ of beans are already GM products, implying that most of food shortage problems are being solved with GMO development.

By 2009, 14,000,000 farms have cultivated GM crops in 25 nations. Total 134,000,000 hectare of land, which is six times the size of the Korean peninsula, is used on cultivating GM products. On this land, $77 \%$ accounts for beans, $49 \%$ for cotton, $26 \%$ for corns, and $21 \%$ for canola, and all these crops are genetically modified. Self-sustenance rate of crops in South Korea does not even reach 30\% [7], a situation that clarifies why South Korea must depend on GMO.

\section{B. Prevention of Further Global Warming}

GMO can also contribute to the recovery of polluted environment that resulted from industrialization, by 
injecting genes to not only crops but also regular plants. This way, GM plants that are resistant to harsh weather will survive and promote afforestation, eventually reviving destroyed mountains and forests and processing noxious emissions such as carbon dioxide. Furthermore, plants could be modified to fix not only carbon but also nitrogen. As for the plants absorbing carbon dioxide, they are widely known to the public as efficient means to improve current environmental situations. The idea about developing nitrogen-fixing plants is fairly new. GMOs are no longer restricted to making up for the damages; they are now expected to contribute to greener Earth.

\section{LIMITATIONS OF GMO AND ITS COUNTERMEASURES}

\section{A. Technical Limitations}

One well-known example of negative consequences resulted from climate change is draught. We have discussed development of drought-resistant GMO, but the procedure is not as simple as it sounds. Researchers must analyze every aspect of drought, from landscapes to locations, and test various types of genes, a costly process. What's worse, development of one GMO takes 10 to 15 years of research, and additional 15 years of monitoring for biosafety and side effects. Plants also need suitable environment to grow and be monitored at, and require agronomical survey. Biochemically appropriate soil must be present at all times.

\section{B. Countermeasures}

Despite negative feedbacks, genetic engineering is considered the most viable solution for climate change, compared to other conventional methods such as crossbreeding. For example, it is viable to crossbreed potatoes of different breeds to end up with finer ones, but it is infeasible to apply the same method for the combination of potatoes and peppers because they are of different species. Genetic engineering can enable extended range of genetic manipulation to create beneficial species and products.

There are countless disputes over GMO, and the solution favored by every researcher and the public is yet to be clarified. Still, the process of finding alternatives and discussing possible methods is one important step to take.

\section{CONCLUSION}

GMO has its advantages and disadvantages. It allows productive cultivation and economical farming without losing crops. Genetic engineering is suitable for solving food shortage and ameliorating the deleterious impacts of global warming. In other words, GMO can not only effectively contribute to make up for the problems resulted from climatic change, but also create a much better environment for Earth. On the other side, its safety issues are yet to be fully addressed along with technological limitations and long-term research period.

Our job is not to treat one side with ignorance but to cover both sides attentively and establish in-depth set of knowledge. After all, genetic engineering is a technology that may forever change the future. We must not downplay this technological feat.

\section{APPENDIX: CASES OF BIOSAFETY ON GMO}

1) The Showa Denko Tryptophan disaster (1989): The Tryptophan disaster killed 37 and caused permanent disabilities in 1,500 people in the United States. The tryptophan was nominated as the culprit, yet it turned out there had been technological faults within the Japanese firm Showa Denko.

2) Brazil nut case (1993): Pioneer Hi-Bred developed modified beans with $2 \mathrm{~S}$ albumin gene from Brazil nut, but trials showed that the beans were allergenic. The problem was the gene itself, not the beans, but still, the firm had to stop its experiment.

3) Pusztai affair (1998): Dr. Arpad Pusztai conducted a study on genetically modified potatoes, and the trial resulted in serious physical problems of his rats. But the process was faulty, not the technology.

4) Case of monarch butterflies (1999): Cornell University researchers reported that GM corn can harm monarch butterflies, but in reality, there rarely is a chance that these butterflies are exposed to the corns, and the government has monitored for years to find nothing strange.

5) Bee experiments of Jena University (2000): A study at Jena University showed that after bees were exposed to GM canola, modified genes were found inside the bees. However, when the study was conducted again four years later, it turned out the study was not scientific at all.

6) The Taco Bell GMO recall (2000): Shells, one of Taco Bell's products, contained GM corn that had not gone through examination by the Food and Drug Administration (FDA). The problem was in faulty distribution process. Fifty million dollars worth of shells were recalled.

7) Case of Mon 863 (2005): In 2005, it was reported that rats which ate Mon 863 had shown significant decrease in liver size. The problem was with the erroneous protocol.

8) Livestock deaths in India (2004): Field observations in Andhra Pradesh in India showed that livestock populations exhibited mortality after exposure to $\mathrm{Bt}$ cotton. But later, Genetic Engineering Approval Committee (GEAC) in India announced that deaths resulted from remaining agricultural chemicals and insecticides, and that $\mathrm{Bt}$ cotton has caused no harms to humans for the past 15 years.

\section{ACKNOWLEDGMENTS}

Professor Hoonbok Yi of Seoul Women's University has kindly revised the Korean version of the thesis and provided helpful advices on the contents. Korea Biosafety Clearing House has provided us with ample research resources and given us an opportunity to participate in its programs.

\section{REFERENCES}

[1] Korea Biosafety Clearing House, Domestic Trend of Research and Development - Statistics on LMO, 2011, pp. 3.

[2] K. Chun, Golden Waves Opening the Future, 2010, pp. 2-3.

[3] K. Kang, D. Lee, and Y. Na, "Climate Change and Our Agriculture," RDA Interrobang, pp. 2, 2011. 
[4] K. Chun, Golden Waves Opening the Future, 2010, pp. 4.

[5] K. Kang, D. Lee, and Y. Na, "Climate Change and Our Agriculture," RDA Interrobang, Rep. 2nd ed. 2011, vol. 33, pp. 3-4.

[6] The Age of Crises of Climate Change, Agriculture, and Food Production, Institute of Mosim and Salim, 2011, vol. 2, pp. 5.

[7] K. Chun, Golden Waves Opening the Future, 2010, pp. 3.

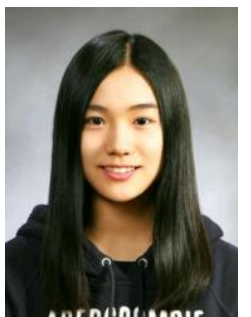

Sungmin Lee was born in Seoul, Republic of Korea on November 13, 1994. She is a senior at Hankuk Academy of Foreign Studies located in Yongin, South Korea. As a high school student, she is planning to major in biological sciences at college.

She has worked at numerous labs in Seoul National University and Chungbuk National University for internship, participated in various biology programs such as Bio Youth Camp and
Bio Youth Mentoring Program, and joined in a conference as a keynote speaker.

Ms. Lee is currently a leader of school biology clubs such as Intuit and Ascenders, and an active member of Biomania and Decabio.

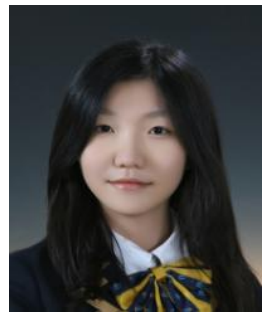

Ha Eun Chun was born in Seoul, Republic of Korea on October 23, 1995. She is a senior at Hankuk Academy of Foreign Studies. She is interested in both biology and chemistry and is planning to major in either molecular biology or organic chemistry.

She has interned at an organic chemistry lab in Seoul National University and a bioengineering lab in Hankuk University of Foreign Studies.

Ms. Chun has recently been to Tsukuba, Japan as a delegate of Korea to participate in Asian Science Camp 2013 with students from across the world. 